\title{
Clinical Study Activity Description
}

National Cancer Institute

\section{Source}

National Cancer Institute. Clinical Study Activity Description. NCI Thesaurus. Code C70960.

A coded terminology representation of a study activity that can be planned, scheduled or performed according to the study protocol. A full representation includes a code and a corresponding textual description of the activity. 